\title{
Morphology of Chorda Tympani Fiber Receptive Fields and Proposed Neural Rearrangements During Development
}

\author{
Charlotte M. Mistretta, ${ }^{1,2}$ Suat Gurkan, ${ }^{1}$ and Robert M. Bradley ${ }^{1,3}$ \\ 'Department of Oral Biology, School of Dentistry, ${ }^{2}$ Center for Human Growth and Development and Center for Nursing \\ Research, and ${ }^{3}$ Department of Physiology, Medical School, University of Michigan, Ann Arbor, Michigan 48109
}

The average number of fungiform papillae in receptive fields of single chorda tympani nerve fibers decreases during development in sheep, and a greater proportion of small receptive fields that are highly responsive to $\mathrm{NaCl}$, compared with $\mathrm{NH}_{4} \mathrm{Cl}$, is acquired. To learn whether there also are developmental differences in the number of taste buds within the papillae in mapped receptive fields, we studied the morphology of receptive fields and fungiform papillae, and also counted fibers in the chorda tympani nerve, in fetal, perinatal, and postnatal sheep.

Whether defined as the number of fungiform papillae or as the number of taste buds within papillae, receptive fields of chorda fibers decrease developmentally. Initially, however, there is an increase, and subsequently a decrease, in the number of taste buds per field. The differences in field size cannot be attributed to developmental alterations in numbers of fungiform papillae because the total number of papillae on the tongue remains constant. The average number of taste buds per papilla, however, also increases and then decreases, and the increase in perinatal animals is accompanied by the appearance of large, multipored taste buds. Because there is a significant relation between fungiform papilla size and number of taste buds in the papilla, papilla size could be one regulating factor for taste bud number. Furthermore, the number of chorda tympani nerve fibers apparently increases up to perinatal stages and then decreases postnatally, providing another potential regulating factor for the number of taste buds.

We propose that in perinatal animals there is a period of hyperinnervation of existing receptive fields by new chorda fibers or branches that induce de novo taste bud development and/or division of existing buds. Later in development, we suggest, there is an elimination of some innervation. The end result is a decrease in the average number of papillae and taste buds in receptive fields. Taste receptive fields are not static during development, but rather undergo substantial changes in morphology and neural organization.

The number of fungiform papillae innervated by a single chorda tympani nerve fiber changes during development in sheep (Nagai et al., 1988). In fetuses at $130 \mathrm{~d}$ of gestation (term, $147 \mathrm{~d}$ ),

\footnotetext{
Received Feb. 24, 1987; revised July 21, 1987; accepted July 22, 1987.

This work was supported by National Science Foundation Grant BNS-8311497 to C.M.M. and R.M.B.

Correspondence should be addressed to Dr. Charlotte M. Mistretta at the above address.

Copyright (C) 1988 Society for Neuroscience $0270-6474 / 88 / 010073-06 \$ 02.00 / 0$
}

the peripheral taste system already manifests the multiple papilla innervation characteristic of adult mammals (Boudreau et al., 1971, 1982; Miller, 1971; Oakley, 1975); one single fiber in the fetus can innervate from 1 to 40 papillae. However, the developing taste system gradually acquires a greater proportion of small receptive fields, and these fields are more responsive to $\mathrm{NaCl}$ than to $\mathrm{NH}_{4} \mathrm{Cl}$ or $\mathrm{KCl}$ (Nagai et al., 1988).

Although the number of fungiform papillae innervated by a single fiber is an appropriate definition of receptive field size in electrophysiological studies, it is in some ways a preliminary definition only. It is not the papilla itself that constitutes the taste receptor organ, but the papilla and associated taste buds. Because a fungiform papilla in sheep and many other mammals each has a variable number of taste buds, the number of papillae in a receptive field will not necessarily equal the number of taste buds.

Therefore, although the number of papillae innervated by one chorda tympani afferent decreases during development, measures of receptive field size based on taste buds might yield different developmental results. There could be a developmental decrease in number of papillae innervated by a fiber accompanied by an increase in average number of taste buds per fungiform papilla. Thus, receptive field size based on number of taste buds could remain the same, or even increase during development, while number of papillae per field decreases.

At present there is no neurophysiological or neuroanatomical indication of whether all taste buds within a fungiform papilla are, in fact, innervated by the same afferent fiber. As discussed in the previous paper (Nagai et al., 1988), it is known that one papilla can be innervated by more than one chorda tympani fiber (Miller, 1971). But does each afferent innervate all taste buds in the papilla, or are some buds innervated by one fiber and some by another? Either proposition is equally tenable ( $\mathrm{Na}$ gai et al., 1988).

It is possible, however, to establish the total number of taste buds within the papillae that are in a receptive field and at least acquire a measure of total available taste buds for the field. This measure, and other supportive data on receptive field and taste bud morphology, can provide a picture of the devcloping peripheral taste system that can be related to development of salt taste sensitivity and that can generate hypotheses about neural rearrangements during maturation of receptive fields.

To learn whether the number of total taste buds in papillae within receptive fields alters during development, we counted buds in all fungiform papillae in receptive fields that had been mapped electrophysiologically (Nagai et al., 1988). Total taste buds per field were calculated for 3 age groups of sheep (fetuses, 


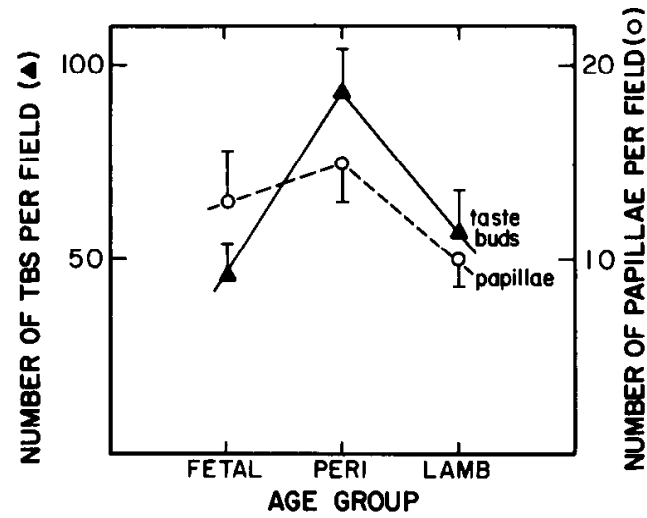

Figure 1. Numbers of taste buds and fungiform papillae in 58 reconstructed receptive fields. Means and SE are presented for 3 age groups. Average number of taste buds per field is larger in perinatal (PERI) animals than in fetuses or lambs.

perinatal animals, and lambs). In addition, we determined the number and size of fungiform papilla on the sheep tonguc, average number of taste buds per papilla, and number of myelinated and unmyelinated fibers in the chorda tympani nerve.

\section{Materials and Methods}

Morphology of receptive fields. As described in the previous paper (Nagai et al., 1988), Suffolk sheep in 3 age groups were studied: 12 fetal lambs at about $130 \mathrm{~d}$ of gestation; 16 perinatal animals studied about 1 week before or after birth (term, $147 \mathrm{~d}$ ); 16 lambs about 1-3 months after birth. Animals were used in electrophysiological experiments to map receptive fields, and tissues were dissected for subsequent histology. Serial coronal sections of fields were cut at $8 \mu \mathrm{m}$ and stained with hematoxylin and eosin.

Specific papillae could be accurately identified in reconstructed maps of 58 receptive fields, and taste buds were counted in the papillae to yield a measure of number of taste buds per field. Serial sections of fungiform papillae were traced and the locations of taste buds marked on each section. By reference between sections and tracings, it was possible to follow and quantify numbers of individual taste buds. Taste buds were characterized as a collection of distinctly staining cells, delimited from surrounding epithelial cells and spanning the depth of the epithelium in fungiform papillae. The presence of a taste pore was not used for identification because in $8 \mu \mathrm{m}$ sections the pore could not always be resolved.

In addition, for all papillae (including those that surrounded receptive fields in dissected tissues but were not part of the field) measures were made of papilla diameter by counting the number of sections in which a papilla appeared. Numbers of taste buds in all papillae were also counted. This yielded data on papilla size and number of taste buds for 923 fungiform papillae in 3 age groups.

Number of fungiform papillae on the tongue. Fungiform papillae were counted on tongues of animals used in other electrophysiological experiments. These included 4 fetuses at $110-114 \mathrm{~d}$ of gestation $(110 \mathrm{~d}$ group), 6 fetuses at $128-132 \mathrm{~d}$ of gestation ( $130 \mathrm{~d}$ group), 6 perinatal animals aged $140 \mathrm{~d}$ of gestation to $5 \mathrm{~d}$ postnatal (perinatal group), and 5 postnatal lambs aged $40-80 \mathrm{~d}$ (lamb group). After dissection the tongues were placed in cold buffered saline and stored in a refrigerator or were fixed in $10 \%$ neutral buffered formalin. Counts of fungiform papillae on refrigerated tongues were made within $24 \mathrm{hr}$ of dissection. Fungiform papillae on fresh and fixed tongues were easily visualized under a dissecting microscope. Pieces of tongue epithelium and some underlying muscle were cut to make flat pieces of tongue tissue. Each papilla on one lateral half of the tongue was counted and marked with a small ink dot. Papillae on all tongues were counted twice, reproducibility being within $93 \%$.

Number of fibers in the chorda tympani nerve. In separate experiments, 2 animals each at 110-112 d of gestation, 130-132 d of gestation, 145 $\mathrm{d}$ of gestation (perinatal), and 40-45 days postnatal (lamb) were perfused via an intracardiac route with $2.5 \%$ phosphate-buffered glutaraldehyde. The chorda tympani nerve was dissected and cut from the point at which it joins the lingual nerve to the point at which it enters the tympanic bulla. The nerve was postfixed in $1 \%$ osmium tetroxide and embedded in Epon. Thin sections of the central end of the chorda were cut ( $100 \mathrm{~nm}$ ), placed on Formvar-coated, single-hole grids, and stained with lead citrate and uranyl acetate. Photographs were made at $2000 \times$, and montages of each whole nerve were reconstructed. The numbers of myelinated and unmyelinated fibers were counted using a digitizing tablet and computer system. Diameters were measured at the widest point of each fiber. Diameters of myelinated fibers included myelin in the measurement. Axon diameter and myelin width are positively correlated in developing myelinated fibers, but the correlation can be somewhat low, suggesting different rates of growth of axon versus myelin (Miller and Dunmire, 1976).

\section{Results}

Numbers of taste buds per receptive field

The total number of taste buds was calculated for 58 receptive fields that had been accurately reconstructed from histological sections. The average number of taste buds per field for fetal, perinatal, and lamb groups was $46(\mathrm{SD}=29, n=15), 93(\mathrm{SD}=$ $53, n=24)$, and $57(\mathrm{SD}=44, n=19)$. These are presented in Figure 1 and compared with the number of fungiform papillae in these reccptive fields. The number of buds per field differed as a function of age $[F(2,57)=6.24, p=0.004]$, and Scheffé posttests demonstrated that there were more buds in perinatal fields than in fetal $(p=0.002)$ or lamb $(p=0.01)$ fields. Thus, based on either the number of papillae (Nagai et al., 1988) or the number of taste buds within these papillae, lamb receptive fields were smaller than those in younger animals. In addition, the number of taste buds per receptive field in perinatal animals was significantly larger than in fetuses. This indicates that there is a developmental increase and subsequent decrease in total available taste buds per receptive field.

\section{Number of fungiform papillae on the tongue}

The total number of fungiform papillae on 21 tongues from 110 and $130 \mathrm{~d}$ fetuses, perinatal animals, and lambs ranged from 426 to 592. As illustrated in Figure 2, the average number of papillae per tongue was $510,545,495$, and 527 for the 4 age groups, and these averages did not differ with age $[F(3,20)=$ $1.03, p=0.40]$. Therefore, differences in receptive field size cannot be attributed to developmental differences in number of fungiform papillae on the tongue.

\section{Number of taste buds per papilla and papilla size}

Data on the average number of taste buds per fungiform papilla for each age group were calculated (Fig. 3, Table 1). These data are based on counts of taste buds in 923 fungiform papillae. The average number of taste buds differed significantly with age $[F(2,922)=26.9, p=0.0001]$. The average value in perinatal papillae ( 6.4 taste buds) was significantly greater $(p<0.05)$ than that in fetuses (3.5) or lambs (5.1), and the average in lambs was greater than that in fetuses $(p<0.05)$.

Although the average number of taste buds per papilla was greatcst in pcrinatal animals, the average in this age group was affected by some extremely high values. Thirteen of 329 total fungiform papillae had more than 25 taste buds per papilla. Inspection of histological sections indicated that the taste buds in fungiform papillae of perinatal sheep frequently have multiple taste pores compared with fetal and lamb buds, which have single pores (Fig. 4). The perinatal taste buds in fungiform papillae resemble those described on the epiglottis of near-term fetuses, in a process of "budding" or division (Bradley et al., 1980). 


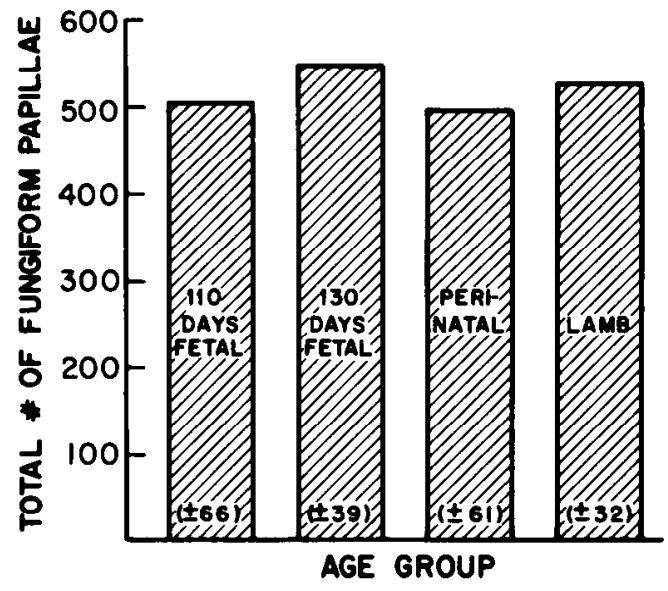

Figure 2. Average number of fungiform papillae on the tongues of sheep in 4 age groups. The SDs are noted in parentheses within histogram bars. Number of papillae on the tongue does not differ across these groups.

The number of taste buds per papilla altered not only as a function of age, but also as a function of receptive field location. Receptive fields from all age groups were categorized according to tongue location as anterior (from the extreme tip to the widest portion of the anterior tongue), middle (from the widest portion of the anterior tongue to the beginning of the intermolar eminence), or posterior (behind the beginning of the intermolar eminence). Papillae in posterior tongue fields had more taste buds than those in anterior or middle fields $[F(2,921)=296.1$, $p-0.0001$ ] (Table 1).

The fungiform papillae themselves also differed in size as a function of age and receptive field location (Table 1). Fungiform papillae increased in diameter during development $[F(2,919)=$ $99.1, p=0.0001]$; papillae in lambs were larger than those in perinatal animals $(p<0.05)$, and perinatal papillae were larger than those in fetuses $(p<0.05)$. Fungiform papillae on the posterior tongue were larger than those on anterior $(p<0.05)$ or middle $(p<0.05)$ locations $[F(2,919)=233.9, p=0.0001]$.

In addition, larger papillae generally accommodated more taste buds. That is, there was a positive correlation between papilla size and number of taste buds in the papilla $[r(920)=$ $0.54, p=0.0001$ ] (Fig. 5). Even if data from the largest papillae are excluded, and the relation is analyzed for papillae from 60 to $500 \mu \mathrm{m}$ only, there is a positive correlation between papilla size and taste bud number $[r(903)=0.44, p=0.0001]$.

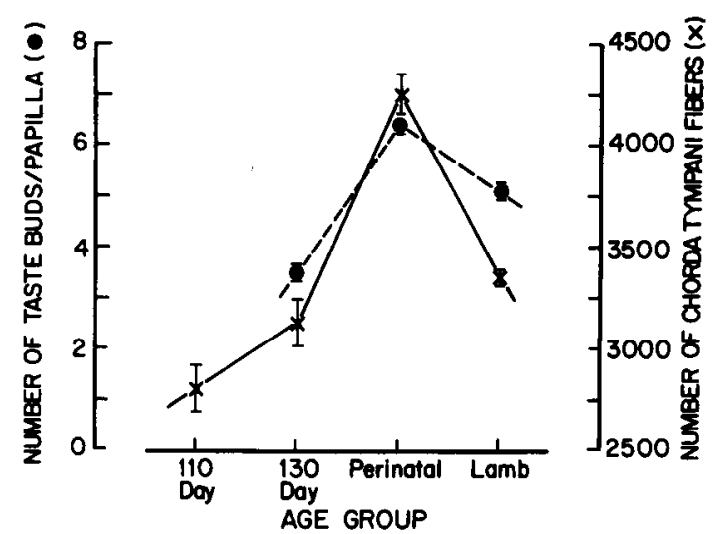

Figure 3. Number of taste buds per fungiform papilla in 3 age groups and total number of chorda tympani nerve fibers in 4 groups. Means and $\mathrm{SE}$ are shown. Average number of taste buds in fungiform papillae in perinatal sheep is greater than in fetal or young lambs. This peak is associated in time with an apparent increase in number of chorda fibers.

\section{Chorda tympani nerve fiber counts}

The number of fibers was counted in chorda tympani nerves from 2 animals in each of 4 age groups (Fig. 3). There are neither sufficient numbers of nerves per age group for statistical analysis nor a sufficient age span to draw firm conclusions about the shape of the function for number of chorda tympani fibers versus age. The data suggest, however, an increase and subsequent loss of fibers, and this is closely associated in time with the increase and subsequent decrease in average number of taste buds per fungiform papilla (Fig. 3). Perinatal animals have an average of 4200 chorda fibers (4173 and 4312 for each animal) compared with 3100 in $130 \mathrm{~d}$ fetuses (3019 and 3251 for each animal) and 3400 in lambs (3337 and 3395), the decrease in numbers between perinatal animals to lambs amounting to $19 \%$. This can be compared with a reported maximum variation of $13 \%$ attributable to individual differences in counts of rhesus monkey optic fibers from various laboratories (Rakic and Riley, 1983a).

Within the total chorda fiber counts, the number of myelinated fibers increases and the number of unmyelinated decreases with age (Fig. 6, inset). Inspection of the data on fiber counts and fiber diameters in Figure 6 suggests that the larger total fiber counts in perinatal animals could be attributed to a subset of very small unmyelinated fibers, which are possibly added at this age. In fetal animals about $25 \%$ of unmyelinated fibers were in the $0-1 \mu \mathrm{m}$ range, whereas in perinatal animals $42 \%$ were in this range and in lambs, $18 \%$.

Table 1. Papilla size and number of taste buds per papilla as a function of age group and tongue location

\begin{tabular}{|c|c|c|c|c|c|c|c|}
\hline & & \multicolumn{3}{|c|}{ Age group } & \multicolumn{3}{|c|}{ Tongue location } \\
\hline & & Fetal & Perinatal & Lamb & Anterior & Middle & Posterior \\
\hline \multirow{3}{*}{$\begin{array}{l}\text { Fungiform papilla } \\
\text { size }(\mu \mathrm{m})\end{array}$} & $\bar{X}$ & 209 & 255 & 303 & 253 & 271 & 535 \\
\hline & SD & 60 & 99 & 70 & 65 & 68 & 167 \\
\hline & $n$ & 204 & 328 & 390 & 747 & 144 & 31 \\
\hline \multirow[t]{3}{*}{ Numbers of buds/papilla } & $\bar{X}$ & 3.5 & 6.4 & 5.1 & 4.4 & 6.0 & 20.5 \\
\hline & SD & 2.1 & 6.7 & 2.9 & 2.8 & 3.1 & 12.7 \\
\hline & $n$ & 204 & 329 & 391 & 748 & 145 & 31 \\
\hline
\end{tabular}



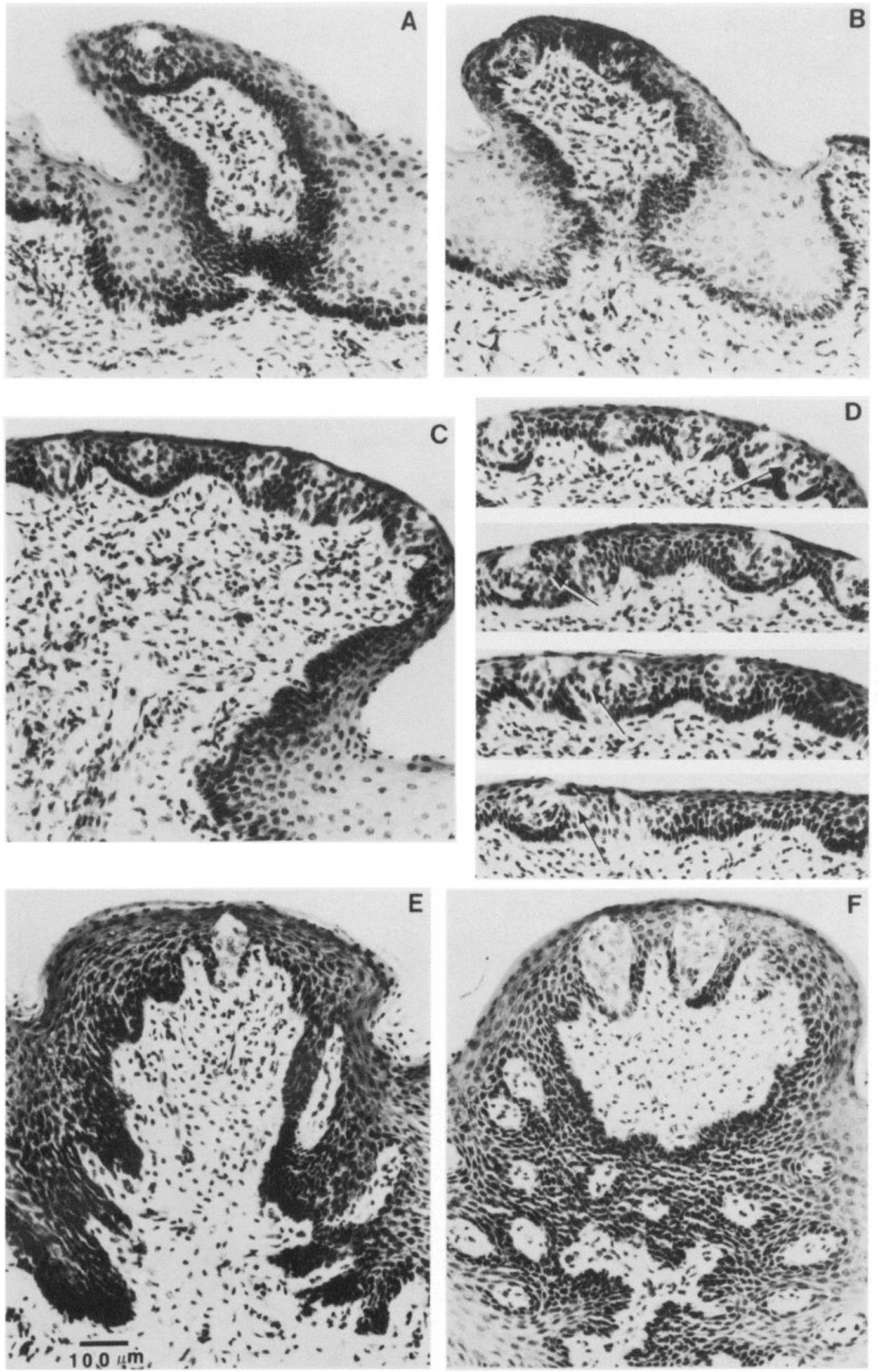

Figure 4. Photomicrographs of fungiform papillae and taste buds from receptive fields in a $130 \mathrm{~d}$ fetus $(A, B)$, a perinatal animal $(C, D)$, and a postnatal lamb $(E, F)$. The perinatal papilla in $C$ is a large one from the posterior tongue, and 6 taste buds are seen in this histological section. Taste buds in $D$ are from 4 different perinatal papillae. In each papilla section, large multipored buds are seen (arrows), possibly in a process of "budding." In fetuses and lambs, there are fewer taste buds per papilla than in perinatal animals. Calibration bar in $E$ applies to all photomicrographs. 


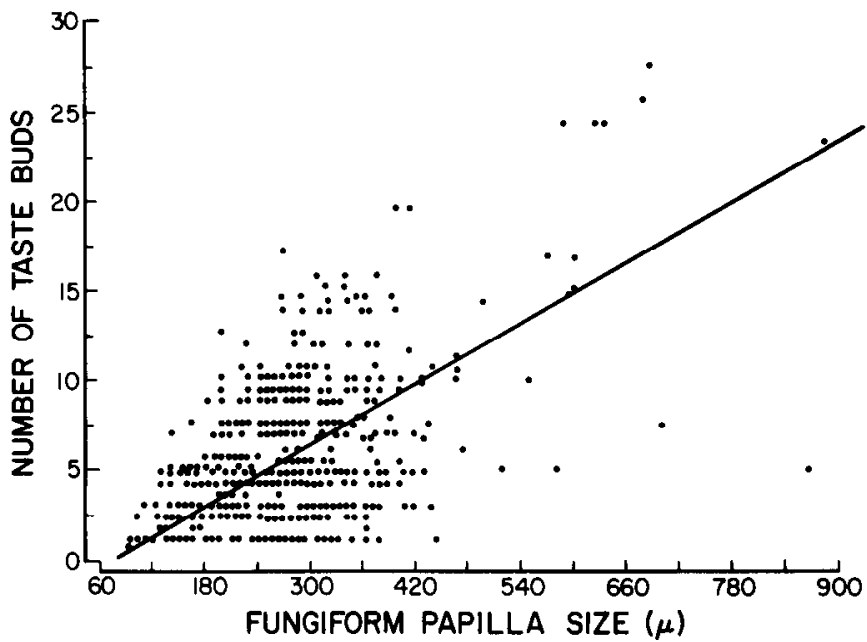

Figure 5. Relation between number of taste buds per fungiform papilla and papilla diameter. There is a significant correlation between taste bud number and papilla size. Straight line is the predicted function for this relation, based on observations of 922 papillae. Due to the large number of observations and the number of overlapping observations, all data points are not shown.

\section{Discussion}

Based either on the number of fungiform papillae or on the total number of taste buds within these papillae, the receptive field size of chorda tympani afferents is smaller in postnatal lambs than in younger animals. This decrease cannot be attributed to a loss of fungiform papillae on the tongue during development since the number of papillae is constant over the ages studied. Thus, there must be some developmental rearrangement of peripheral taste organs and associated innervation that results in the acquisition of a greater proportion of small receptive fields.

Converging evidence from this study suggests the processes involved in this developmental reorganization. Quantitative data across 3 age groups indicate that the number of fungiform papillae per receptive field remains relatively high from about 130 $\mathrm{d}$ of gestation to birth $(147 \mathrm{~d})$ and then decreases postnatally. During this period, the total number of fungiform papillae on the tongue remains the same. Total number of taste buds in papillae per receptive field increases and then decreases. The average number of taste buds per papilla also increases and then decreases. There is, however, a net gain in the average number of taste buds per papilla from fetus to lamb and an associated increase in the size of fungiform papillae during this period.

The developmental increase and decrease in the number of taste buds per receptive field and of taste buds per papilla coincide in time with an apparent increase and decrease in number of chorda tympani nerve fibers. These receptor organ and neural alterations are concomitant with an acquisition of increased responsiveness to $\mathrm{NaCl}$ compared with other salts-a greater proportion of chorda tympani fibers and associated receptive fields respond with higher frequencies to $\mathrm{NaCl}$ than to $\mathrm{NH}_{4} \mathrm{Cl}$ or $\mathrm{KCl}$ as development progresses (Nagai et al., 1988).

Overall, the data lead to the proposition that there is a period of hyperinnervation of fungiform papillae in perinatal animals that induces formation of increased numbers of taste buds. Farbman (1965) has demonstrated that taste bud differentiation in the postnatal rat is subsequent to, and presumably dependent upon, ingrowth of fibers into fungiform papillae. In perinatal sheep, some of the additional buds could be formed de novo

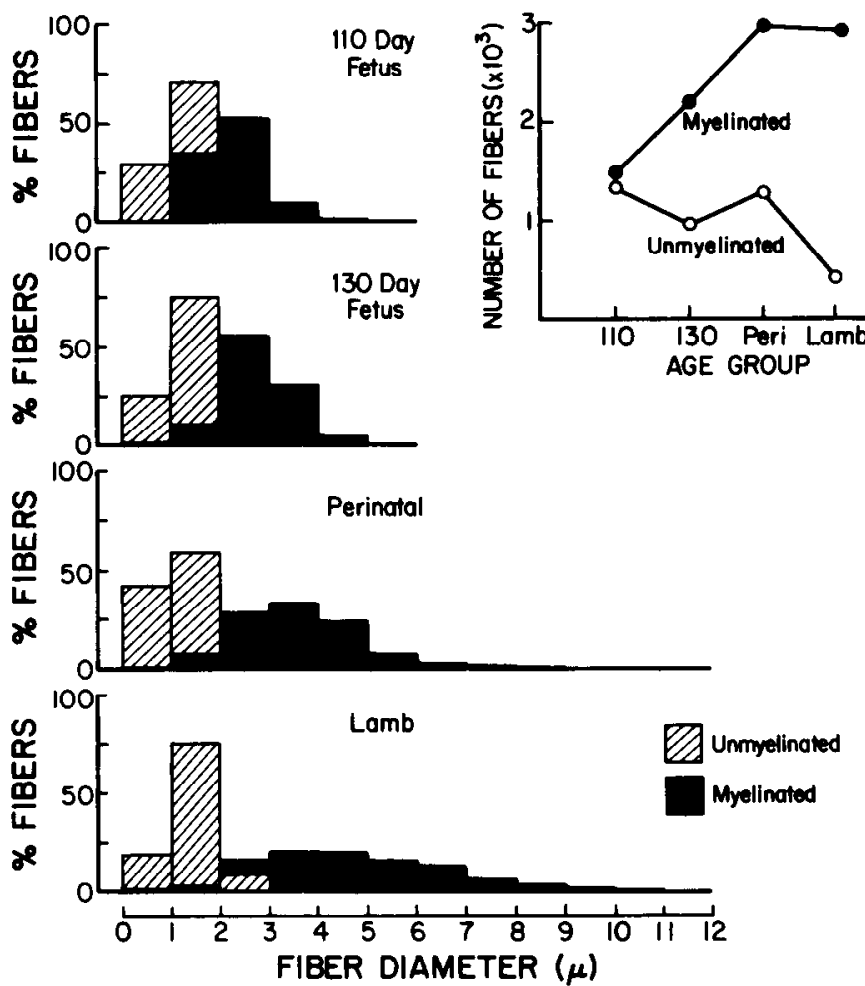

Figure 6. Distributions of the percentage of myelinated and unmyelinated chorda tympani nerve fibers of various fiber diameters in 4 age groups. In $110 \mathrm{~d}$ fetuses, there were no myelinated fibers in the $0-1 \mu \mathrm{m}$ range, and in other age groups, $<0.5 \%$. In fetuses and perinatal animals, there were $<1 \%$ unmyelinated fibers in the $2-3 \mu \mathrm{m}$ range. Inset, Total number of myelinated and unmyelinated fibers in all age groups. During development, the number of myelinated fibers increases and that of unmyelinated fibers decreases; however, in perinatal animals there is an apparent increase in the proportion of very small unmyelinated fibers in the $0-1 \mu \mathrm{m}$ range.

and some through a process of division or budding. A budding process in taste bud development has been proposed by Bradley and coworkers, who observed large, multipored buds in fungiform papillae in human fetuses (Bradley and Stern, 1967) and in the epiglottis of fetal sheep (Bradley et al., 1980) but not in older animals. Large multipored buds also were observed in fungiform and circumvallate papillae of fetal dogs (Ferrell, 1984) and in rabbit foliate papillae (Heidenhain, 1914). Similar taste buds were seen in perinatal fungiform papillae in this study.

We propose that, subsequent to the period of perinatal hyperinnervation, there is a postnatal period of elimination of chorda tympani branches within fungiform papillae that mediates loss of taste buds per papilla. The elimination could be related to the observed overall loss of fibers in the chorda tympani nerve. A developmental increase and subsequent decrease in optic nerve fibers has been reported in fetal rhesus monkeys (Rakic and Riley, 1983b), with a continuing postnatal loss of fibers. On the other hand, if the total number of fibers remains the same, terminal branches within papillae could be eliminated. Since there is a positive relation between taste bud number and papilla size, it can be suggested that papilla size participates in regulating the extent of afferent innervation and, thus, the number of buds. In addition, neural competition for taste buds and papillae and/or alterations in neural activity could lead to elimination of some innervation, as proposed for other developing neural systems (Fawcett and O'Leary, 1985; Thompson, 1986). 
There is a developmental reorganization of innervation patterns in many other parts of the mammalian nervous system. In the periphery, the reorganization frequently involves a progression from larger, diffuse to smaller, narrow innervation patterns. For example, there is a developmental reduction in the multiple innervation of cells in autonomic ganglia (Lichtman, 1977 ) and in the number of muscle fibers contacted originally by each motor axon (Van Essen, 1982). In the present experiments, it should be recalled that we determined the number of taste receptor organs (papillae and associated taste buds) innervated by single afferent fibers. Each taste bud contains about 40-60 cells, and each of these presumably contains numerous synapses. Thus, although taste receptive fields become smaller during development, we have no indication of possible changes in synapse number or type.

The end result of the proposed developmental period of hyperinnervation and subsequent elimination would be fewer taste buds per fungiform papilla and fewer papillae and taste buds in receptive fields. The idea that papillae are more extensively innervated at one developmental stage than others is testable, and more detailed observations of taste buds in perinatal sheep may lead to conclusions about the proposed budding process. However, these hypotheses require some important assumptions.

As mentioned in the introduction, we can determine the total number of taste buds within papillae in mapped receptive fields, but we must then assume that all taste buds within each papilla are innervated by the same afferent. In addition, it is assumed that the increase in the number of chorda tympani nerve fibers in perinatal animals and the subsequent decrease in lambs is attributable to afferent innervation. Of total chorda tympani fibers in adult rat, about $80 \%$ of the myelinated and $30 \%$ of the unmyelinated fibers are afferents, the balance being efferents (Farbman and Hellekant, 1978; Miller et al., 1978). We do not know whether afferent and efferent fibers develop in parallel or whether either the increase or decrease in chorda tympani fibers is attributable to a gain or loss of primarily efferent fibers. These assumptions require further experimental validation. Neuron counts in the geniculatc ganglion cannot resolve these problems because the ganglion includes neurons not associated with taste (Boudreau et al., 1971). Chorda fiber counts that exclude efferents will be necessary.

Finally, we have noted the limitations of studying only 3 age groups (Nagai et al., 1988). In rhesus monkeys, counts of optic nerve axons from early gestation to adulthood have demonstrated a rapid, early prenatal increase in number, followed by a rapid decrease before midgestation, and a subsequent slower decrease postnatally (Rakic and Riley, 1983b). A more detailed examination of pre- and postgestational receptive field morphology and innervation in sheep is essential to fully describe the developmental functions that accompany receptive field maturation in this species. However, the fetal to postnatal period we have studied definitely encompasses one of the major alterations in neural taste response-namely, to various salts (Mistretta and Bradley, 1983).

Attendant to the morphological reorganization of receptive fields is a shift in taste receptor responsiveness. The smaller receptive fields that are acquired developmentally are more responsive to $\mathrm{NaCl}$ than to $\mathrm{NH}_{4} \mathrm{Cl}$ (Nagai et al., 1988). Larger receptive fields are more responsive to $\mathrm{NH}_{4} \mathrm{Cl}$. Do incoming chorda fibers have an inherent "type" and thereby specify newly induced taste buds to become sodium sensitive? Or do incoming fibers innervate fields that become smaller through competitive regulation, and sodium sensitive through mechanisms essentially independent of the new innervation?

Clearly, the taste system is not static during development. Observations on receptive ficlds and associated innervation demonstrate periods of receptor and neural increase and decrease, and suggest possible mechanisms of neuronal sprouting, hyperinnervation, competition, and retraction or loss in the process of receptive field development. Whatever the operative mechanisms, increased receptor responsiveness to $\mathrm{NaCl}$ develops in the context of radical alterations in peripheral taste fields.

\section{References}

Boudreau, J. C., B. E. Bradley, P. R. Bierer, S. Kruger, and C. Tsuchitani (1971) Single unit recordings from the geniculate ganglion of the facial nerve of the cat. Exp. Brain Res. 13: 461-488.

Boudreau, J. C., J. J. Oravec, and N. K. Hoang (1982) Taste systems of goat geniculate ganglion. J. Neurophysiol. 48: 1226-1242.

Bradley, R. M., and I. B. Stern (1967) The development of the human taste bud during the foetal period. J. Anat. 101: 743-752.

Bradley, R. M., M. L. Cheal, and Y. H. Kim (1980) Quantitative analysis of developing epiglottal taste buds in sheep, J. Anat. 130: 25-32.

Farbman, A. I. (1965) Electron microscope study of the developing taste bud in rat fungiform papilla. Dev. Biol 11: 110-135.

Farbman, A. I., and G. Hellekant (1978) Quantitative analysis of the fiber population in rat chorda tympani nerves and fungiform papillae. Am. J. Anat. 153: 509-522.

Fawcett, J. W., and D. D. M. O'Leary (1985) The role of electrical activity in the formation of topographic maps in the nervous system. Trends Neurosci. 8: 201-206.

Ferrell, M. F. (1984) Taste bud morphology in the fetal and neonatal dog. Neurosci. Biobehav. Rev. 8: 175-183.

Heidenhain, M. (1914) Uber die Sinnesfelder und die Geschmacksknopsen der Papilla foliata des Kanninchens. Arch. Mikrosk. Anat. Entwmech. 85: 365-560.

Lichtman, J. W. (1977) The reorganization of synaptic connexions in the rat submandibular ganglion during post-natal development. $\mathbf{J}$. Physiol. (Lond.) 273: 155-177.

Miller, A. J., and C. R. Dunmire (1976) Characterization of the postnatal development of superior laryngeal nerve fibers in the postnatal kitten. J. Neurobiol. 7: 483-494.

Miller, I. J. (1971) Peripheral interactions among single papilla inputs to gustatory nerve fibers. J. Gen. Physiol. 57: 1-25.

Miller, I. J., M. M. Gomez, and E. H. Lubarsky (1978) Distribution of the facial nerve to taste receptors in the rat. Chem. Senses Flavor 3: 397-411.

Mistretta, C. M., and R. M. Bradley (1983) Neural basis of developing salt taste sensation: Response changes in fetal, postnatal, and adult sheep. J. Comp. Neurol. 215: 199-210.

Nagai, T., C. M. Mistretta, and K. M. Bradley (1988) Developmental decrease in size of peripheral receptive fields of single chorda tympani nerve fibers and relation to increasing $\mathrm{NaCl}$ taste sensitivity. J. Neurosci. 8: 64-72.

Oakley, B. (1975) Receptive fields of cat taste fibers. Chem. Senses Flavor 1: 431-442.

Rakic, P., and K. P. Riley (1983a) Regulation of axon number in primate optic nerve by prenatal binocular competition. Nature 305 . 135-137.

Rakic, P., and K. P. Riley (1983b) Overproduction and elimination of retinal axons in the fetal rhesus monkey. Science 219: 1441-1444.

Thompson, W. J. (1986) Changes in the innervation of mammalian skeletal muscle fibers during postnatal development. Trends Neurosci. 9: 25-28.

Van Essen, D. C. (1982) Neuromuscular synapse elimination: Structural, functional and mechanistic aspects. In Neuronal Development, N. C. Spitzer, ed., pp. 333-371, Plenum, New York. 